Discussion Paper 122

Institute for Empirical Macroeconomics

Federal Reserve Bank of Minneapolis

250 Marquette Avenue

Minneapolis, Minnesota 55480-0291

August 1997

\title{
Electronic Money: The End of Inflation?
}

\author{
Ramon Marimon* \\ European University Institute, \\ Universitat Pompeu Fabra, CEPR \\ and NBER
}

Juan Pablo Nicolini*

Universidad Torcuato Di Tella

and Universitat Pompeu Fabra

Pedro Teles*

Banco de Portugal and

Universidade Católica Portuguesa

\footnotetext{
*We want to thank V. V. Chari, Hal Cole, Pat Kehoe, Narayana Kocherlakota, Neil Wallace, Warren Weber and participants at seminars at the Federal Reserve Bank of Minneapolis, the European University Institute and the 1997 SED Meetings in Oxford for helpful comments and suggestions. All errors are ours. This paper is based on research conducted while Teles was visiting the Universidad Di Tella, the European Forum at the European University Institute and the Federal Reserve Bank of Minneapolis. Teles thanks hospitality at these Institutions as well as the financial support of JNICT. The views expressed herein are those of the authors and not necessarily those of the Federal Reserve Bank of Minneapolis or the Federal Reserve System.
} 


\begin{abstract}
We study economies where government currency and electronic money, drawn from interest bearing deposits in private financial intermediary institutions, are full substitutes. We analyze the impact of competition on policy outcomes under different assumptions regarding: the objectives of the central bank, the ability of the monetary authorities to commit to future policies, and the legal restrictions - in the form of reserve requirements—on financial intermediaries. Electronic money competition can discipline a revenue maximizing government and result in lower equilibrium inflation rates, even when there is imperfect commitment. The efficient Friedman rule policy, of zero nominal interest rates, is only implemented if the government maximizes households preferences, in which case, electronic money competition may either have no role, or weaken the incentive effects of the "reputational mechanism." We also show how an independent choice of the reserve requirements can be an effective policy rule to enhance the disciplinary role of electronic money competition.
\end{abstract}




\section{Introduction}

Most developed countries have experienced a drastic reduction of inflation rates in the last quarter of this century, from the double digit numbers of the mid-seventies to the very low -say, below 2.5\%- numbers at the end of the nineties. High inflation episodes seem to be problems of the past, as if society had become immune to the disease. This success in curbing down inflation has been usually attributed to a better monetary policy management. In particular, the major discipline, in terms of monetary policy of more independent central banks and, in the case of the European Union, the design and willingness to comply with the Maastricht Treaty have received most of the credit. But not only policies and institutions have changed in this period, payments systems have gone through a major transformation. In particular, electronic payments have risen in most developed countries and are expected to rise even more in the future. For example, Humphrey et al. (1996) find that "in all (fourteen) developed countries but the United States, electronic payments have been either the sole or the primary reason for the 34 percent rise in total non-cash payments between 1987 and 1993"( p. 935) ${ }^{1}$.

Maybe the predominant view among academic (and central bank) economists is right, and clever policy and institutional design have created the right incentives to discipline the monetary authorities as to achieve price stability. But maybe, the right incentives have been created by the wide spread development and use of cash substitutes. Who deserves most credit? Our aim in this paper is not to elucidate this; although an implication of the paper will be that the role of electronic money in curbing down inflation probably has been undervalued.

Our aim is to study whether electronic money competition -or, more generally, competition from interest-bearing inside monies - enhances price stability. In particular, we study the relation between competition and policy outcomes under different assumptions regarding: the objectives of the central bank, the ability of the monetary authorities to commit to future policies, and the legal restrictions -in the form of reserve requirements- on financial intermediaries. The central contribution of this paper is to show how these

\footnotetext{
${ }^{1}$ The US is the exception because a larger fraction of non-cash transactions are paper transactions. As it will become clear, however, our definition of "electronic money" is fairly broad and encompasses most non-credit, non-cash, forms of payment, such as most Bank cards, debit cards, smart cards, etc.
} 
differences affect the way in which electronic money competition disciplines monetary authorities.

Although ours is a theoretical exploration it also relates to common everyday experience. Cash cards are now a generalized means of payments in most developed countries. The purchases using these cards are immediately deducted from a bank account. The seller receives the amount at the end of the month and pays a small commission to the card issuer (1\% or smaller). The bank accounts on which the cash cards are issued typically pay interest. We call these deposits, electronic money. From the point of view of the buyer using electronic money is equivalent to using a checking book. The fact that electronic money is interest bearing distinguishes it from currency. Currency by its very nature cannot pay nominal interest. Instead, electronic money can pay nominal interest on the average balance at a very small cost. In this sense the electronic money can dominate currency. For the seller this card means that he will be reimbursed. Only a very small fraction of transactions cannot be performed with these cards and these are the transactions in very small amounts. So one could say that currency and the deposits on which the cards are issued are very close substitutes in transactions. In other words, technological change is blurring the distinction between different components of M1 (and among components of broader monetary aggregates).

The close substitutability of cash cards with currency makes this world with electronic money resemble a free banking world, i. e., the historical episodes of relatively unrestricted banking systems, as the "Free Banking Era" in the United States (1837-63), Scotland (1716-1844), New England (1820-1860), Canada (1817-1914) and other historical experiences. In most cases, these episodes preceded the introduction of legal restrictions preventing the currency competition of privately issued bank notes ${ }^{2}$. In other words, one can see the financial history of currency supply as a process that in many countries went first through a process of laissez-faire, in which the supply of currency resembled that of other services, to become a -possibly, the most- regulated service: with, in particular, the state monopolization of currency supply, together with legal (e.g., regulations of financial intermediaries) and technological (e.g., the cost of small denomination transactions)

\footnotetext{
${ }^{2}$ See Schuler (1992) for an account of historical episodes of free banking. See also Dowd (1992) and, in particular, the scholarly editorial work of White (1993) for a broad perspective of the literature on free banking; to which one must necessarily add the writings of Hayek (1974) and (1978).
} 
restrictions that prevented the circulation of interest-bearing assets as means of exchange. Supposedly, these regulations were to overcome instability problems often associated with the free banking era. But, high inflation episodes showed that regulation was no guarantee for price stability. More recently, in many countries steps have been taken to change the procedures by which monetary policy is conducted (e.g., independence of central banks) and to liberalize financial services. But, more than to a pursuit of laissez-faire, the rise in electronic money is due to a technological change (not suppressed by regulations) which makes it possible for households and firms to consolidate their cash and deposits portfolios.

Parallel (sometimes ahead, often behind) to these historical transformations of payment systems, there has been a long academic debate on how monetary policy should be conducted and, in particular, on the role of currency competition. The debate goes back to Adam Smith and Sir James Stuart, whose views were shaped by the concurrent "free banking" experience of Scottish banks (Checkland, 1975). Such debate has seen many supporters of free competition making an exception when it comes to money (as Friedman, 1959). For a long time, fervent supporters of free currency competition seemed to preach in isolation (notably, Hayek (1974 and 1978); also Rockoff, 1975). More recently, there has been a reappraisal of the selfregulating properties of free banking ${ }^{3}$. In spite of its many ramifications, at the roots of the debate there have been two classical arguments: i) "money is a natural monopoly", and ii) "money is a service that, as other services, can be more efficiently allocated with free competition". Most of the recent empirical and theoretical reappraisal has undermined the first view, but this by no means implies the success of the second view.

The standard "currency competition" view -as, for example, has been expressed by Hayek - is based on a "Bertrand competition" argument, according to which competition will drive the price (return) of money to its marginal cost (costs of setting up the system being sunk). That is, an "optimal monetary policy" can be the result of competition, more than of a monopolistic policy. In other words, the argument is the same as the one used to priva-

\footnotetext{
${ }^{3}$ See, for example, Calomiris and Kahn (1996), Dowd (1992), King (1983), Rolnick and Weber (1983), Selgin (1987), Selgin \& White (1987), Vaubel (1985), and, more generally, White (1993) . Another example of "reappraisal" has been the modified view of Friedman regarding the role of central banks as monopolistic suppliers (see Friedman and Schwartz,1986).
} 
tize many sectors (electricity, railroads, etc.) that had also gone through the process of "starting private" and later being protected as "natural monopolies," by, recently, being opened to market competition. Should money follow the same path? There are, however, two flaws on this "Bertrand competition" argument, when applied to fiat money. First, that while competition may reduce inflation (we see below, in which sense), it may not be enough as to achieve an efficient outcome. In particular, it may not be enough as to implement the Friedman rule of zero nominal interest rates, which requires transfers to private agents. Second, if suppliers of currency can not commit to their future actions, then competition may loose its bite. The reason being that while currencies compete on their promised rates of return, once agents hold a particular currency there may be an incentive for the issuer to inflate the price of goods of the corresponding currency, reducing this way the outstanding liabilities. That is, the currency supplier has an incentive to default on the promise made while competing with other currencies.

The time-inconsistency problem in implementing monetary policies, is well understood, what is less clear is whether competition can help to overcome this problem (or whether it may even worsen it). In other words, the role of competition can not be analyzed independently from the commitment problem $^{4}{ }^{5}$. While now we start to understand how policies can be designed in environments without full commitment (see, for example, Chang (1996), Chari \& Kehoe (1990), Ireland (1994), Stokey, 1991), with -in part- the exception of Taub (1985) the "currency competition" argument has abstracted from the reputational problem ${ }^{6}$. This is the central theme of this paper.

We focus on a world with a central bank that monopolizes the supply of cash and private financial intermediaries that provide "electronic money," not only for its practical relevance, but also because it has a distinct feature: only the central bank can manipulate the price level. In contrast, in a world

\footnotetext{
${ }^{4}$ It should be noticed that both problems arise from the sequential nature of policy decisions. The parallel with Industrial Organization regulation problems should also be clear: it is very different to compete in an auction for the rights to provide a future stream of services at an (enforceable) price, than to compete for the rights to provide the service and to set future prices.

${ }^{5}$ In a tax competition framework, Kehoe (1989) shows that, when capital is allocated to the different countries after the savings decision, but before the government decision on taxes, then competition can still reduce the tax rates.

${ }^{6} \mathrm{~A}$ shortcoming that had not been unnoticed (see, for example, Hellwig (1985)).
} 
of competing currencies, suppliers can affect their own distinct prices. That is, when government currency circulates, our economies resemble those of "free banking with a distinct base money," as envisioned, for example, by Becker (1956); (see also White (1993), v.III, Part I). On the other hand, when electronic money dominates government currency (or when, as a result of government's default on promised policies, agents decide to only use electronic money), then our cashless economies resemble those of "competitive payments systems without base money", as envisioned, for example, by Black (1970); (see also White (1993), v.III, Part III). Our framework also allows us to study the role of reserve requirements as a possible policy instrument affecting the competition between electronic money and government money.

In a follow up paper we will study a world of "competing currencies" in its more strict sense. Such a world is closer to the one studied by Taub (1985). Taub studies two commitment regimes: one with full commitment, "time inconsistent" (non-stationary) competing policies, and another in which policies are constrained to be "time consistent" (stationary). He shows that in the commitment case, the Friedman rule emerges as the competitive outcome, while in the second case the competitive outcome is inefficient, a result he argues goes in favor of the "natural monopoly" argument. Although, as we have said, our economies have a different competitive structure, our analysis of the non-commitment case also differs in that, following the more recent literature on "reputational mechanisms," we consider the strategic interaction between the government and private agents; that is, in considering whether to default from past promises, the government takes into account agents' reactions to such deviations ${ }^{7}$. We also obtain that, with "electronic money", the outcome of competition differs with different degrees of commitment, but our results do not support, in general, the "natural monopoly" view.

In our model, "reputation" and "competition" are two disciplinary mechanisms that, as it turns out, do not always complement each other. To better understand this interplay, we study two contrasting hypothesis regarding Central Bank's objectives. First (in Sections 3 and 4) we assume a "revenue maximizing" Central Bank, second (in Section 5) a "representative" Central

\footnotetext{
${ }^{7}$ In the language of game theory, Taub (1985) only considers sequential equilibria that are a stationary sequence of one period actions, while we consider the general class of sequential equilibria, which allows for the possibility of having the commitment outcome as a sequential equilibrium path; that is, it allows for having the commitment policy as a "sustainable plan" (in the language of Chari and Kehoe (1990)).
} 
Bank; that is, a central bank which shares the same preferences as the representative household. The later hypothesis dominates the current academic literature on monetary policy design and is attractive to central bank economists. However, it is not clear which hypothesis is a better description of reality, and, therefore, we analyze both (leaving to the reader the exercise of taking convex combinations).

In Section 2 we present the model. In Section 3 we show how "electronic money" helps to curb down inflation when the government is revenue maximizer. In a certain sense, our results contrast with Hayek's claims ${ }^{8}$ that competition among private issuers of money drives the nominal interest rates to zero (as in Taub (1985)). In the world with electronic money, the presence of the money issuing competitive banks drives the intermediation gains to the marginal intermediation cost. It is the difference between the interest rate on bonds and the interest rate on deposits used for the purpose of transactions that is determined by the competitive equilibrium. Inflation under full commitment is driven down as a result of competition between the issuer of currency and the anonymous suppliers of inside money, together with the reduction of financial intermediation costs.

In Section 4 we study the non-commitment case. The rent-seeking commitment policy is time inconsistent, but in considering default, the Central Bank must take into account that agents may move to electronic money (i.e., depriving the Central Bank of future seignorage rents). It turns out that, as long as there is no deflation under the full commitment policy, such a policy can be sustained by reputation. An odd feature of this result is that to sustain the full commitment policy, the financial intermediation sector can not be too efficient. The interest rate spread between bonds and money must guarantee non-negative future rents to the Central Bank. However, reserve requirements affect this spread. This, on the one hand, means that if reserve requirements are determined outside the Central Bank, they can be used as an effective policy instrument; but, on the other hand, it also means that if they are determined by the same Central Bank then the positive role of competition can be undermined.

In Section 5 we study the case of a "representative" government. Not surprisingly, under perfect commitment, the Friedman rule is the policy chosen by the Central Bank (who acts as a Ramsey planner), therefore, there is

\footnotetext{
${ }^{8}$ For a world of "competing currencies", see Hayek (1974) and (1978)
} 
no role for "electronic money" competition (unless it becomes a technology which is more efficient than the use of cash).

However, the Ramsey's solution is time-inconsistent and, therefore, with imperfect commitment, the government must balance the gains of deviating from the prescribed Friedman rule, against the costs of a deviation. After a deviation, households do not use cash. When cash is the only liquid asset, this autarchic outcome is most undesired by the "representative" government. In contrast, the "punishment" is less severe when households can still use electronic money. As a result, the presence of electronic money competition makes the "reputation" disciplinary effect less effective. We show however, that if agents cannot adjust their portfolios instantaneously, a benevolent government may be deterred from deviating and implement the Friedman rule, in spite of the lack of commitment and the presence of electronic money competition. Section 6 concludes the paper.

\section{Electronic money}

\subsection{Equilibria with electronic money}

In this section we characterize the competitive equilibria where transactions are performed with currency and electronic money. We also characterize the equilibria where only electronic money is used for transactions. Electronic money are interest bearing deposits that are made liquid because they can be used for transactions, through the use of electronic debit cards. So they are a close substitute for currency.

The economy is populated by a large number of identical infinitely lived households, financial intermediaries and a government. The households have preferences given by

$$
V=\sum_{t=0}^{\infty} \beta^{t}\left[u\left(c_{t}^{1}\right)+u\left(c_{t}^{2}\right)+\alpha h_{t}\right]
$$

where $c_{t}^{1}, c_{t}^{2}$ and $h_{t}$ represent respectively consumption of a cash good, consumption of a credit good and leisure in period $t$. Assuming that leisure enters linearly in the utility function is in no way essential, but significantly simplyfies the derivations. The utility function $u$ shares the usual assumptions of concavity and differentiability. 
The representative household chooses sequences of consumption of goods and leisure $\left\{c_{t}^{1}, c_{t}^{2}, h_{t}\right\}_{t=0}^{\infty}$ and sequences of assets $\left\{M_{t+1}, b_{t+1}^{h}, E_{t+1}\right\}_{t=0}^{\infty}$, given sequences of prices, $\left\{P_{t}, R_{t+1}^{b}, I_{t+1}^{e}\right\}_{t=0}^{\infty}$, to satisfy the following budget and cash-in advance constraints:

$$
\begin{gathered}
M_{t+1}+P_{t} b_{t+1}^{h}+E_{t+1} \leq M_{t}+P_{t} R_{t}^{b} b_{t}^{h}+I_{t}^{e} E_{t}-P_{t}\left(c_{t}^{1}+c_{t}^{2}\right)+P_{t}\left(1-h_{t}\right), t \geq 0 \\
P_{t} c_{t}^{1} \leq M_{t}+E_{t}, t \geq 0
\end{gathered}
$$

where $M_{0}, R_{0}^{b} b_{0}^{h}$, and $I_{0}^{e} E_{0}$ are given and a no-Ponzi games condition is satisfied.The variable $b_{t+1}^{h}$ denotes the number of units of the produced good, in period $t$, that entitle the household to $R_{t+1}^{b} b_{t+1}^{h}$ units of the produced good in period $t+1$. $M_{t+1}$ is end of period currency held from period $t$ to $t+1$. $E_{t+1}$ is the electronic money. Currency and electronic money are perfect substitutes. $I_{t+1}^{e}$ is the nominal rate of return on these deposits. $1-h_{t}$ is the labor supply and $P_{t}$ is the price level. The particular timing is the one in Svensson (1985), meaning that the agents enter the period with money balances that are used for transactions that same period.

Since currency does not pay nominal interest, a competitive equilibrium where both currency and electronic money circulate must have $I_{t}^{e}=1$. We define

$$
I_{t+1}^{b} \equiv \frac{P_{t+1}}{P_{t}} R_{t+1}^{b}, \quad t \geq 0
$$

Then an equilibrium in this economy must also satisfy:

$$
\begin{array}{ccrl}
\frac{u^{\prime}\left(c_{t+1}^{1}\right)}{\alpha} & =I_{t+1}^{b}, & & t \geq 0 \\
\frac{u^{\prime}\left(c_{t}^{2}\right)}{\alpha}=1, & t \geq 0 \\
R_{t+1}^{b}=\beta^{-1}, & t \geq 0
\end{array}
$$

If $I_{t}^{e}<1$, only currency circulates and (5) - (7) must hold. If instead $I_{t}^{e}>1$, then equation (5) is replaced by

$$
\frac{u^{\prime}\left(c_{t+1}^{1}\right)}{\alpha}=1+I_{t+1}^{b}-I_{t+1}^{e}, t \geq 0
$$

meaning that the cost of holding money is only the difference between the return on bonds and the return on money that in this case is not zero. 
Financial intermediaries The financial intermediaries ${ }^{9}$ hold government bonds, $P_{t} b_{t+1}^{e}$, and issue interest bearing deposits that can be used for purchases, $E_{t+1}$, through the use of electronic debit cards. There is an intermediation cost measured in units of labor, $n_{t}^{e}$. We assume that the financial intermediaries operate a Leontieff-fixed coefficients technology that produces electronic money and uses as inputs bonds and labor. The total amount of electronic money equals the amount of bonds held and equals $P_{t} \frac{n_{t}^{e}}{\theta}$ where $\theta$ is the labor cost of one unit of deposits:

$$
\begin{gathered}
E_{t+1}=P_{t} b_{t+1}^{e} \\
n_{t}^{e}=\theta \frac{E_{t}}{P_{t}}
\end{gathered}
$$

The cash flow of the financial intermediaries, in period $t$, is

$$
C F_{t}^{e}=E_{t+1}-P_{t} b_{t+1}^{e}-E_{t} I_{t}^{e}+P_{t} b_{t}^{e} R_{t}^{b}-P_{t} n_{t}^{e}, t \geq 0
$$

The zero-profit condition is

$$
I_{t+1}^{b}-I_{t+1}^{e}=\theta, t \geq 0
$$

Government The government issues money, $M_{t+1}^{s}$, and real debt, $d_{t+1}$, to finance government expenditures, $g_{t}$. Government expenditures are a credit good. We abstract from alternative sources of tax revenues so that the government budget constraints are

$$
M_{t+1}^{s}+P_{t} d_{t+1} \leq M_{t}^{s}+P_{t} R_{t}^{b} d_{t}+P_{t} g_{t}, t \geq 0
$$

The present value budget constraint can be written as

$$
\sum_{t=0}^{\infty} q_{t} g_{t} \leq \sum_{t=0}^{\infty} q_{t+1}\left(I_{t+1}^{b}-1\right) \frac{M_{t+1}^{s}}{P_{t+1}}-\frac{M_{0}}{P_{0}}-R_{0}^{b} d_{0}
$$

where $q_{t}=\frac{1}{R_{1}^{b} \ldots R_{t}^{b}}, t \geq 1, q_{0}=1$.

\footnotetext{
${ }^{9}$ See Lucas (1993), for a general equilibrium model with inside money.
} 
Market clearing The market clearing conditions are

$$
\begin{gathered}
c_{t}^{1}+c_{t}^{2}+g_{t}=1-h_{t}-\theta \frac{E_{t}}{P_{t}}, t \geq 0 \\
d_{t}=b_{t}^{h}+b_{t}^{e}, t \geq 0 \\
M_{t}=M_{t}^{s}, t \geq 0
\end{gathered}
$$

The competitive equilibrium where both currency and electronic money circulate must satisfy:

$$
I_{t+1}^{b}=1+\theta
$$

In this equilibrium the real values of currency and electronic money are indeterminate. Therefore the level of government expenditures is also indeterminate. For the utility function that is linear in leisure, consumption is determinate but leisure is not. To abstract from this indeterminacy we assume that when the cost of holding the two types of money is equal, the households opt for currency.

If $I_{t}^{e}>1$, only electronic money circulates. The price level and the nominal interest rates are indeterminate. The real variables are not affected by the multiplicity in the price levels and the nominal interest rates ${ }^{10}$.

In these economies with private issuers of electronic money, the nominal interest rates are not driven down to zero, as claimed in general by the free banking literature and in particular by Hayek $(1974,78)$. The reason is that private issuance of electronic money is compatible with interest payments on money, where else that literature tended to exclude this possibility. Free entry into this market drives the spread between the rate on bonds and the rate on electronic money down to the cost of supplying the monetary substitutes.

\subsection{Reserve requirements}

Reserve requirements can be understood as a technological constraint or instead as a legal requirement. We assume that, as it is in most cases, legal requirements on iddle reserves are a fraction of total deposits. Therefore

\footnotetext{
${ }^{10}$ This would not be the case if the interest rate spread was not a constant but rather, a function of the interest rate, as in Woodford (1995).
} 
every bank faces a fixed coefficients technology with deposits, labor input and reserves, such that

$$
\begin{gathered}
(1-z) E_{t+1}=P_{t} b_{t+1}^{e} \\
Z_{t+1}=z E_{t+1} \\
P_{t} n_{t}^{e}=\theta E_{t}
\end{gathered}
$$

where $Z_{t+1}$ are reserves and $z$ is the linear reserve requirement. In period $t$, the cash flow of the financial intermediaries is

$$
C F_{t}^{e}=E_{t+1}-P_{t} b_{t+1}^{e}-Z_{t+1}-E_{t} I_{t}^{e}+P_{t} b_{t}^{e} R_{t}^{b}+Z_{t}-\theta E_{t}, t \geq 0
$$

The zero profit condition is therefore

$$
I_{t+1}^{b}-I_{t+1}^{e}=\theta+z\left(I_{t+1}^{b}-1\right), t \geq 0
$$

The government budget constraint is not affected by the presence of the reserve requirements, but the government money supply must now, in equilibrium, be equal to the demand by the households and by the financial intermediaries.

$$
M_{t}+Z_{t}=M_{t}^{s}, t \geq 0
$$

The competitive equilibrium where both currency and electronic money can circulate must now satisfy:

$$
I_{t+1}^{b}=1+\frac{\theta}{1-z}
$$

\section{Equilibria with commitment}

\subsection{Rent-seeking government}

In this section we consider optimal policies under the assumption that the government maximizes revenue ${ }^{11}$. Thus, we assume that the government preferences are described by an objective function

$$
\sum_{t=0}^{\infty} \beta^{t} G\left(g_{t}\right)
$$

\footnotetext{
${ }^{11} \mathrm{In}$ section 5, we will analyze the implications of assuming a benevolent, Ramsey government.
} 
where, for standard reasons, the function $G$ is assumed to be increasing and concave. The government maximizes this function subject to the budget constraint and subject to the competitive equilibrium conditions by choice of $\left\{M_{t}^{s}, d_{t}, g_{t}\right\}_{t=0}^{\infty}$.

First, note from equation (7) that the equilibrium real rate of interest is constant ${ }^{12}$. Using this result together with (4), (5) and (6) to eliminate prices in the government budget constraint (12) we obtain the following implementability constraint

$$
\sum_{t=0}^{\infty} \beta^{t} g_{t}=\sum_{t=0}^{\infty} \beta^{t+1}\left(I_{t+1}^{b}-1\right) F\left(I_{t+1}^{b}\right)-\frac{M_{0}}{P_{0}}-R_{0}^{b} d_{0}
$$

where $F$ is real demand for currency. If the government chooses $I^{b}{ }_{t+1} \leq 1+\theta$, so that only currency circulates, then $F=M$, where $M$ is the function obtained from the first order condition $\frac{u^{\prime}\left(c_{t+1}^{1}\right)}{\alpha}=I_{t+1}^{b}$, so that $c_{t+1}^{1}=m_{t+1}=$ $M\left(I_{t+1}^{b}\right)$. If instead $I_{t+1}^{b}>1+\theta$, then $F\left(I_{t+1}^{b}\right)=0$. The government maximizes revenues by setting the monetary policy so that $\frac{M_{0}}{P_{0}}=0$.

Given that $G$ is assumed to be strictly concave and that the discount factor of the government is equal to the real interest rate, the government's problem can be simplified as the choice of a sequence of nominal interest rates that maximizes

$$
g=(1-\beta) \sum_{t=0}^{\infty} \beta^{t+1}\left(I_{t+1}^{b}-1\right) F\left(I_{t+1}^{b}\right)-(1-\beta) R_{0}^{b} d_{0}
$$

If in the objective function we replace the function $F$ for $M$ so that there are no constraints on the choice of the nominal interest rates arising from competition with electronic money, the solution is stationary and corresponds to the maximum of the Laffer curve, $I^{b *}$. For the isoelastic utility function, $u(c)=\frac{c^{1-\sigma}}{1-\sigma}$, with $\sigma<1$, as $I_{t+1}^{b}$ becomes arbitrarily large, the revenue $\left(I_{t+1}^{b}-1\right) M\left(I_{t+1}^{b}\right)$ tends to zero. Also when $I_{t+1}^{b}=1$, the revenue is zero. The maximum of the Laffer curve corresponds to a positive, finite value for the interest rate. We assume that the preferences specification is such that the value $I^{b *}$ is higher than $1+\theta$. This means that the revenue maximizer government would not choose an interest rate lower than that value. Should

\footnotetext{
${ }^{12}$ This results from the linear structure of the utility function. Note that this assumption rules out the time inconsistency problem discussed in Lucas and Stokey (1983).
} 
the government choose $I_{t+1}^{b}>1+\theta$ ? In this case the revenue is zero. So the government will choose $I_{t+1}^{b}=1+\theta$, for all $t \geq 0$, and raise $\theta F(1+\theta)$ of seigniorage revenue, per period. Since from the zero profit condition for the financial intermediaries $I_{t+1}^{b}=I_{t+1}^{e}+\theta$, it must be that $I_{t+1}^{e}=1$. We have shown that the following proposition holds:

Proposition 1 Assume $I^{b *} \geq 1+\theta$, where $I^{b *}$ maximizes $\left(I^{b}-1\right) M\left(I^{b}\right)$. Then the commitment solution for the revenue maximizing government is $I_{t+1}^{b}=1+\theta$, and $I_{t+1}^{e}=1$, for all $t \geq 0$.

Electronic money drives the nominal interest rates to levels that only account for the intermediation cost, i.e. the cost of providing the alternative means of transactions to the households. In an environment without electronic money, the government would set the monetary policy so that the maximum revenue may be obtained. This would mean that the interest rate would be $I^{b *}$, and the revenues would be $g=\beta\left(I^{b *}-1\right) F\left(I^{b *}\right)-(1-\beta) R_{0}^{b} d_{0}$. Since government revenues are assumed to be worthless, the presence of electronic money is welfare improving.

The optimal commitment solution is time inconsistent. In this solution, at time zero, the government decides to hold real bonds issued by the private sector that are exchanged for money and the gross nominal interest rate is constant over time and set at $1+\theta$. At time $t$, if the government could revise the plan, the problem would be to choose $\left\{I_{s+1}^{b}\right\}_{s=t}^{\infty}$ to maximize

$$
g^{t}=(1-\beta) \sum_{s=t}^{\infty} \beta^{s+1-t}\left(I_{s+1}^{b}-1\right) F\left(I_{s+1}^{b}\right)-(1-\beta)\left[\frac{M_{t}}{P_{t}}+\beta^{-1} d_{t}\right]
$$

where $g^{t}$ are the government expenditures from period $t$ on. The optimal policy is to set the price level at time $t$ arbitrarily large. This way the government reduces the real value of the nominal liabilities. So the interest rate plan for $I_{t}^{b}=\frac{P_{t}}{\beta P_{t-1}}=1+\theta$ would not be optimal, for a government that could decide sequentially.

The discussion above suggests that lack of commitment can drastically change the nature of currency competition. In fact, the governmental agency that issues currency competes with the private issuers of money by announcing an interest rate. However, as was shown above, the equilibrium nominal interest rates, under commitment, are not time consistent and therefore those 
announcementes make no sense. As a result, one could be lead to think that an equilibrium with electronic money-only would be the sole sequential equilibrium outcome. In fact this is not the case. The credible threat of reversion to an equilibrium where currency does not circulate might be enough to sustain the equilibrium solution under commitment that was just described.

This means that currency competition when there is at least one big player, that can influence the price level, is of a very different nature from competition under commitment. In section 4 , we determine the sequential equilibria in an environment where the government precisely cannot commit to the announced policy. We now proceed to analyzing the impact of reserve requirements on the characterization of the optimal policy under commitment.

\subsection{Reserve requirements}

The government budget constraint can be written as

$$
\sum_{t=0}^{\infty} \beta^{t} g_{t} \leq \sum_{t=0}^{\infty} \beta^{t+1}\left(I_{t+1}^{b}-1\right) F\left(I_{t+1}^{b}\right)-\frac{M_{0}}{P_{0}}-\frac{Z_{0}}{P_{0}}-R_{0}^{b} d_{0}
$$

where $F$ is the real demand for currency and reserves. If the government chooses $I^{b}{ }_{t+1} \leq 1+\frac{\theta}{1-z}$, so that only currency circulates, then again $F=M$, where $M$ is the function $m_{t+1}=M\left(I_{t+1}^{b}\right)$, obtained from the first order condition $\frac{u^{\prime}\left(m_{t+1}\right)}{\alpha}=I_{t+1}^{b}$. If instead $I^{b}{ }_{t+1}>1+\frac{\theta}{1-z}$, then

$$
F\left(I_{t+1}^{b}\right)=z M\left(1+\theta+z\left(I^{b}{ }_{t+1}-1\right)\right) .
$$

Note first that reserve requirements do not change the nature of the problem concerning the period zero balances. Therefore, the government maximizes revenues by setting the monetary policy so that $\frac{M_{0}}{P_{0}}=\frac{Z_{0}}{P_{0}}=0$. The government's problem can be simplified as the choice of a sequence of nominal interest rates that maximizes

$$
g=(1-\beta) \sum_{t=0}^{\infty} \beta^{t+1}\left(I_{t+1}^{b}-1\right) F\left(I_{t+1}^{b}\right)-(1-\beta) R_{0}^{b} d_{0}
$$

If the reserve requirement, $z$, is taken to be exogenous, there are three types of solutions. First, if the intermediation cost, $\theta$, is very low, eventually 
zero, then, for currency to circulate, the nominal interest rate must be very low. Therefore, the government cannot get almost any seigniorage revenue from currency. In this case, the solution is to set a nominal interest rate such that only electronic money circulates, and that maximizes the seigniorage imposed on reserve requirements, the only demand for currency in the equilibrum. Therefore, the government maximizes

$$
z\left(I^{b}-1\right) M\left(1+z\left(I^{b}-1\right)\right) .
$$

This means that the choice of the nominal interest rate is $I^{b}=\frac{I^{b *}-(1-z)}{z}$ where $I^{b *}$ is the interest rate that maximizes the Laffer curve, defined as $\left(I^{b}-1\right) M\left(I^{b}\right)$.

A second possible solution can occur for intermediate values of $\theta$ and $z$. This is a case in which the maximum of the Laffer curve is to the right of $1+\frac{\theta}{1-z}$. Thus, electronic money does impose an upper bound on the nominal interest rate. However, the government is better off by imposing a low - relative to the maximum of the Laffer curve- interest rate but having a larger tax base, rather than imposing a higher interest rate but collecting the tax on a fraction of the money in circulation. In this case, the solution is the corner $I^{b}=1+\frac{\theta}{1-z}$. Here only currency circulates, as well.

Finally, if $\theta$ and $z$ are high enough, it might be that $I^{b *}<1+\frac{\theta}{1-z}$, in which case $I^{b *}$ will be the solution, and only currency circulates. The value of this solution is $g=\beta\left(I^{b *}-1\right) M\left(I^{b *}\right)-(1-\beta) R_{0}^{b} d_{0}$. In this case, the intermediation costs combined with the reserve requirements imply that electronic money cannot compete with currency.

If the same agency that picks the inflation tax also determines the reserve requirements, then the optimal solution is to set $z$, so that

$$
1+\frac{\theta}{1-z}=I^{b *}
$$

In this case the government gets the revenue corresponding to the maximum of the Laffer curve and only currency circulates ${ }^{13}$.

\footnotetext{
${ }^{13}$ If the intermediation cost was zero then this solution could be reproduced by establishing complete backing, $z=1$, and setting the nominal interest rate to $I^{b *}$.
} 


\section{Equilibria without commitment}

\subsection{Rent-seeking governments}

As it is clear from the discussion above, the government policies are not time consistent. Thus, in this section we consider reputational equilibria where the competitive households and financial intermediaries condition their decisions on the contemporaneous histories of government policies. This framework naturaly drives the analysis to the interactions between competition and reputation.

Once we allow expectations of the agents to depend on histories, there is always an equilibrium where only electronic money circulates. This equilibrium is time consistent. The households expect that the return on electronic money is higher than the one on currency, $I_{s+1}^{b}>1+\theta, s \geq t$, and the real value of currency they decide to hold is equal to zero. Given this the demand for real balances is zero and any monetary policy is optimal. In particular, sticking to the agents' expectations is optimal. Since $F\left(I_{s+1}^{b}\right)=0, s \geq t$, and $\frac{M_{t}}{P_{t}}=0$, then the value of this equilibrium outcome is

$$
V_{t}^{W S E}=-(1-\beta) R_{t}^{b} d_{t}
$$

where $W S E$ stand for worst sequential equilibrium. This equilibrium outcome is not the worst equilibrium under commitment but it is the worst sequential equilibrium. Note that a feasible policy for the government, at any time is to follow a constant money rule. In this case, independently of what the private agents' optimal response is, the government can achieve, at least, the value $V_{t}^{W S E}$. Therefore, there cannot be a sequential equilibrum with a value lower than $V_{t}^{W S E}$.

In the tradition of Barro and Gordon (1983) and in line with Chari and Kehoe(1990), Stokey (1991), Ireland (1994) and Chang (1996), we apply Abreu (1988)'s optimal penal codes and use the reversion to the worst sequential equilibrium as the means of supporting equilibrium outcomes. Any sequential outcome can be supported by an equilibrium in which private expectations display this trigger like behavior. The value of the worst sequential equilibrium outcome is compared to the value of the revenue maximizing equilibrium $(R M E)$ outcome,

$$
V_{t}^{R M E}=\beta\left(I^{b}-1\right) M\left(I^{b}\right)-(1-\beta)\left(M\left(I^{b}\right)+R_{t}^{b} d_{t}\right)
$$


where $I^{b}=1+\theta$. The $R M E$ equilibrium is sequential when its value is higher then the one of the WSE. This is true when

$$
\pi \geq 0
$$

meaning that the government has to get a positive gain from issuing money. The proposition follows:

Proposition 2 The optimal policy under commitment is a sequential equilibrium path if the intermediation cost, $\theta$, is large enough that the equilibrium inflation rate is non-negative.

Proof. It was shown above that the optimal policy under commitment is a sequential equilibrium whenever $\pi \geq 0$. This means that $I^{b} \geq \beta^{-1}$. But $I^{b}=1+\theta$. So it is necessary that $\theta \geq \beta^{-1}-1$

In order to understand the effect of the presence of electronic money on the equilibrium level of inflation, it is important to compare these results to the solutions in an environment where the competition from electronic money is not present. If there was only currency then the commitment solution would be to set the nominal interest rate so that the maximum of the Laffer curve is obtained. As long as this value is positive, the solution is sequential. In this case, the punishment is autarchy, but from the perspective of a revenue maximizing government this has the same value as the electronic money-only equilibrium.

One could think that competition with electronic money would drive the nominal interest rates to values that could not be sustained, because the costs of defaulting would be substantially reduced. This is partially true. Competition with electronic money drives the inflation tax to a low level under commitment, but this solution is a sequential equilibrium provided the intermediation cost is big enough, to guarantee the benefits from the future issuing of currency.

An interesting feature of the previous result is that the sustainability of the commitment solution does not depend on the discount factor. In the reputational literature (see Barro and Gordon (1983)), the monetary equilibrium under commitment is sustained only if the discount factor is high enough. In those models, there is a short run benefit of increasing the money supply and a long run cost, starting the following period. The 
government follows the equilibrium path under commitment if the present value of the long run cost is sufficiently high. In our case, a deviation from the equilibrium path has immediate effects. The newly issued pieces of paper are valueless at the time of the deviation.

If the commitment solution is not a sequential equilibrium then the only sequential equilibrium path is the equilibrium without currency. However since currency is replaced by electronic money this "autarchic" solution may not be such a great disaster. In the way we have modelled money, there is a liquidity effect so that the switch to electronic money implies the destruction of the real value of liquid assets and so the cash good is not consumed in that period. However from the following period on the households would be using electronic money as the means of exchange, supporting the cost of intermediation.

We have seen that the requirement for the commitment solution to be sequential is that the intermediation costs are not too low. One way of guaranteeing that these costs are big enough is to establish reserve requirements. That way competition with electronic money is made softer and so the revenues from issuing money may be increased to the point that the revenue maximizing government is not interested in defaulting. In the next section we analyze the effects of considering reserve requirements, for the equilibria without commitment.

\subsection{Reserve requirements}

The presence of reserve requirements, by forcing the banks to hold noninterest bearing assets, has the effect of softening the competition with electronic money. In the extreme case of a $100 \%$ reserve requirement, electronic money competition is killed.

Note that with reserve requirements, the condition for currency to dominate electronic money becomes

$$
I^{b} \leq 1+\frac{\theta}{1-z}
$$

Therefore, from the viewpoint of the government, an economy with intermediation costs equal to $\theta$ and reserve requirements equal to $z$ is equivalent to an economy without reserve requirements and an intermediation cost equal to 


$$
\theta^{\prime}=\frac{\theta}{1-z}
$$

The solution with an endogenous reserve requirement corresponds to the maximum of the Laffer curve so it is equivalent to the solution without electronic money. In that case the non-committed government is able to sustain a high level of the inflation tax.

For any exogenous level of the reserve requirement, if the commitment equilibrium is such that only currency circulates, then the punishment is to revert to electronic money but with arbitrarily large nominal interest rates so that the solution is autarchy. So for the revenue maximizing government the effect of the reserve requirements is to raise the value of the equilibria under commitment, improving the conditions for sustainability of the equilibria. This result is summarized in the following proposition:

Proposition 3 Whenever $\theta<\beta^{-1}-1$, it is possible to sustain an equilibrium solution under commitment if the reserve requirements are high enough, as long as the inflation rate that maximizes the Laffer curve is non-negative.

Proof. Let the reserve requirement $z$ be such that $1+\frac{\theta}{1-z}=\beta^{-1}$. If the inflation rate that maximizes the Laffer curve is non-negative, the equilibrium under commitment for the interest rate must be $I^{b} \geq \beta^{-1}$, since the government can at least get the revenues from the currency-only equilibrium with $I^{b}=\beta^{-1}$. As we showed in the previous proposition, the currency-only equilibrium is sequential as long as the equilibrium inflation rate is non-negative, i.e $I^{b} \geq \beta^{-1}$. Since the case where $I^{b}>\beta^{-1}$ must correspond to higher revenues, the equilibrium under commitment is sustainable

Reserve requirements as a policy tool Reserve requirements can act as a means of guaranteeing the sustainability of the commitment solution for the revenue maximizing government. If the commitment solution is not sustainable the solution will be the autarchic equilibrium that is a sequential equilibrium. In terms of welfare in this case with reserve requirements the punishment is very severe, since the households can reduce the revenues to the government only by driving electronic money out of circulation. The 
households would be better off paying the inflation tax that brings the highest revenue to the government. The endogeneity of the reserve requirement, softens the asymmetry of the punishment to the households and to the government since it would be an off-equilibrium outcome.

An obvious policy recommendation is the careful and independent use of the reserve requirement instrument as a means of obtaining sustainability of the revenue maximizing, commitment solution.

\section{The case of a "representative" government}

In this section we briefly show how the results change when we assume that the government maximizes the utility function of the consumers. The standard Ramsey problem assumes fixed government expenditures. As the ability to collect seigniorage will be limited by the efficiency of the financial intermediaries, we allow the government to levy consumption taxes, $\tau_{t}$, to ensure that expenditures can be financed. As we will see, under fairly general elasticity conditions, a "representative" government, with full commitment, will implement the Friedman rule of zero nominal interest rates after the initial period, but may decide to increase or decrease the initial price level, in order to affect comsumption in the initial period. This behavior follows from the basic principle of optimal taxation of levying higher taxes on relatively more inelastic goods and it is the basis of the time inconsistency of optimal monetary policy.

Since, at any period, the current consumption of cash goods is relatively more inelastic, the government has an ex-post incentive to deviate from the Friedman rule path. Such a deviation, however, may result in a liquidity crunch if we assume that agents take time to replenish their cash holdings. As a reaction to the government's deviation, agents may not want to hold cash in the future and, as a result, the value of current real money balances drops to zero, making it impossible for agents to consume the cash good in the current period. When government's money is the only liquid asset, such a currency collapse results in zero consumption of the cash good in the future too. When electronic money can also be used for cash purchases, agents can - after a government's deviation - substitute cash for electronic money, and, therefore, they only suffer the current period liquidity crunch and the future loss of having a positive nominal interest rate that covers financial 
intermediation costs.

In summary, when a government's deviation is followed by a reaction of the private agents triggering a currency collapse, agents - and the "representative government" - are better off if electronic money is a substitute liquid asset. In other words, the presence of electronic money weakens the deterrence of a currency collapse, making it more difficult to sustain the full commitment path of zero nominal interest rates. Nevertheless, for a "representative government" the liquidity crunch effect may — by itself - be a sufficient deterrence factor as to prevent any deviation from the Friedman rule. We now proceed with an explicit analysis of the problem.

The consumer's problem is as before, except for the presence of a tax on consumption. Thus, preferences are represented by (1) and the budget and cash-in-advance constraints are

$$
\begin{gathered}
M_{t+1}+p_{t} b_{t+1}^{h}+E_{t+1} \leq p_{t}\left(1-h_{t}\right)-\left(1+\tau_{t}\right) p_{t}\left(c_{t}^{1}+c_{t}^{2}\right)+M_{t}+p_{t} R_{t}^{b} b_{t}^{h}+I_{t}^{e} E_{t} \\
\left(1+\tau_{t}\right) p_{t} c_{t}^{1} \leq M_{t}+E_{t}
\end{gathered}
$$

The first order conditions of the consumer's problem are given by

$$
\begin{aligned}
\beta^{t} u^{\prime}\left(c_{t}^{1}\right)-\left(1+\tau_{t}\right) p_{t}\left(\lambda_{t}+\nu_{t}\right) & =0 \\
\beta^{t} u^{\prime}\left(c_{t}^{2}\right)-\left(1+\tau_{t}\right) p_{t} \lambda_{t} & =0 \\
\beta^{t}(-\alpha)+p_{t} \lambda_{t} & =0 \\
-\lambda_{t}+\left(\lambda_{t+1}+\nu_{t+1}\right) & \leq 0 \\
-\lambda_{t}+\left(I_{t+1}^{e} \lambda_{t+1}+\nu_{t+1}\right) & \leq 0 \\
-\lambda_{t}+I_{t+1}^{b} \lambda_{t+1} & =0
\end{aligned}
$$

It follows from these equations that

$$
\left(1+\tau_{t}\right)=\frac{u^{\prime}\left(c_{t}^{2}\right)}{\alpha} \quad t \geq 0
$$

Furthermore, if $I_{t+1}^{e} \leq 1$,

$$
I_{t+1}^{b}=\frac{u^{\prime}\left(c_{t+1}^{1}\right)}{u^{\prime}\left(c_{t+1}^{2}\right)} \quad t \geq 0
$$

while if $I_{t+1}^{e}>1$, 


$$
\frac{u^{\prime}\left(c_{t+1}^{1}\right)}{u^{\prime}\left(c_{t+1}^{2}\right)}=1+I_{t+1}^{b}-I_{t+1}^{e}=(1+\theta) \quad t \geq 0
$$

where the last equality follows from the zero profit condition in financial intermediation.

\subsection{Optimal policy under commitment}

The solution under commitment is a Ramsey (1927) optimal taxation problem, in the line developed by Lucas and Stokey (1983) and Chari, Christiano and Kehoe (1993). The objective of the government is to maximize the welfare of the representative household, subject to feasibility and competitive equilibrium constraints, i. e., equations (25) to (32) and (13).

We consider first the case where $I_{t}^{e} \leq 1$ (i.e., (30) is satisfied with equality), which means that only currency circulates. In order to eliminate prices, we substitute (27) - (32) and (26) into (25) (pre-multiplied by $\lambda_{t} \beta^{-t}$ ), we have the following consolidated condition

$$
\beta u^{\prime}\left(c_{t+1}^{1}\right) c_{t+1}^{1}+u^{\prime}\left(c_{t}^{2}\right) c_{t}^{2}-\alpha\left(1-h_{t}\right)+\alpha b_{t+1}^{h}-\alpha b_{t}^{h} \beta^{-1}=0
$$

Now, if we add the discounted restrictions (33), imposing appropriate terminal conditions, we obtain the implementability constraint

$$
u^{\prime}\left(c_{0}^{2}\right) c_{0}^{2}-\alpha\left(1-h_{0}\right)+\alpha b_{0} \beta^{-1}+\sum_{t=1}^{\infty} \beta^{t}\left[u^{\prime}\left(c_{t}^{1}\right) c_{t}^{1}+u^{\prime}\left(c_{t}^{2}\right) c_{t}^{2}-\alpha\left(1-h_{t}\right)\right]=0
$$

We can now define the Ramsey problem as

$$
\max \sum_{t=0}^{\infty} \beta^{t}\left[u\left(c_{t}^{1}\right)+u\left(c_{t}^{2}\right)-\alpha\left(1-h_{t}\right)\right]
$$

subject to $(34)$ and

$$
c_{t}^{1}+c_{t}^{2}+g-\left(1-h_{t}\right) \leq 0
$$

Let $\sigma_{u}(c)=-\frac{u^{\prime \prime}\left(c_{t}\right) c_{t}}{u^{\prime}\left(c_{t}\right)}$, that is $\sigma_{u}(c)$ is the coefficient of relative risk aversion for $u(\cdot)$ at $c\left(1 / \sigma_{u}\left(c_{t}\right)\right.$ is the price elasticity of $\left.c_{t}\right)$. The first order interior conditions for this problem are

$$
u^{\prime}\left(c_{t}^{1}\right)\left[1+\gamma\left(1-\sigma_{u}\left(c_{t}^{1}\right)\right)\right]=\theta_{t} \beta^{-t} \quad t \geq 1
$$




$$
\begin{gathered}
u^{\prime}\left(c_{0}^{1}\right)=\theta_{0} \\
u^{\prime}\left(c_{t}^{2}\right)\left[1+\gamma\left(1-\sigma_{u}\left(c_{t}^{2}\right)\right)\right]=\theta_{t} \beta^{-t} \quad t \geq 0 \\
\alpha(1+\gamma)=\theta_{t} \beta^{-t} \quad t \geq 0
\end{gathered}
$$

The above equations characterize the Ramsey equilibrium and show the time inconsistency problem when the price elasticity is different from one (see Nicolini, $1997^{14}$ ). In particular,

$$
\begin{gathered}
I_{t+1}^{b}=\frac{u^{\prime}\left(c_{t+1}^{1}\right)}{u^{\prime}\left(c_{t+1}^{2}\right)}=\frac{1+\gamma\left(1-\sigma_{u}\left(c_{t+1}^{2}\right)\right)}{1+\gamma\left(1-\sigma_{u}\left(c_{t+1}^{1}\right)\right)} \quad t \geq 0 \\
\frac{u^{\prime}\left(c_{0}^{1}\right)}{u^{\prime}\left(c_{0}^{2}\right)}=1+\gamma\left(1-\sigma_{u}\left(c_{0}^{2}\right)\right) \\
\left(1+\tau_{t}\right)=\frac{u^{\prime}\left(c_{t}^{2}\right)}{\alpha}=\frac{1+\gamma}{1+\gamma\left(1-\sigma_{u}\left(c_{t}^{2}\right)\right)} \quad t \geq 0
\end{gathered}
$$

It follows that the solution of the Ramsey policy is the Friedman rule and the corresponding equilibrium is stationary from period one on. In the context of optimal taxation rules, the Friedman rule means that the two goods, cash and credit, are taxed at the same rate. This is the optimal solution since the utility function is homothetic in the two goods and separable in leisure. These are the conditions for uniform taxation of Atkinson and Stiglitz (1972), as pointed out by Lucas and Stokey (1983) and Chari, Christiano and Kehoe (1993). Furthermore, if the price elasticity is greater than one $\left(\sigma_{u}<1\right)$, the consumption in period 0 of the cash good is lower than the consumption from period 1 on. That is, there is a higher tax on the initial cash good (with a price elasticity of one ). This is condensed in the following proposition:

Proposition 4 Assume $\sigma_{u}(c)=\sigma_{u}$. In a Ramsey equilibrium, $I_{t+1}^{b}=1$ and $\tau_{t}=\tau, t \geq 0$. If $\sigma_{u}<1 c_{0}^{1}<c_{0}^{2}=c_{t+1}^{2}=c_{t+1}^{1}, t \geq 0$.

This solution is an equilibrium even if electronic money is a liquid asset since the zero profit condition implies that $I_{t}^{e}=I_{t}^{b}-\theta$ and, since $\theta>0$, the currency printed by the government dominates in rate of return electronic money when the government implements the Ramsey policy; in particular, the nominal interest rate on electronic money is negative. The last argument

\footnotetext{
${ }^{14}$ See also Calvo (1978).
} 
also shows that there can not be a Ramsey equilibrium in which households only use electronic money (if private financial intermediation is more costly than central bank intermediation) as stated in the following corollary

Corollary 5 When $\theta>0$, the Ramsey solution is such that $I_{t+1}^{e} \leq 1, t \geq 0$, so that electronic money does not circulate.

Suppose that there was an equilibrium with $I_{t}^{e}>1$, then $\frac{u^{\prime}\left(c_{t}^{1}\right)}{u^{\prime}\left(c_{t}^{2}\right)}=(1+\theta)$ for $t \geq 1$. However, this relation between cash and credit goods could have been achieved by the "representative government" (in the previous case of $\left.I_{t}^{e} \leq 1\right)$, by setting $I_{t}^{b}=(1+\theta)$, in which case the government would have collected seignorage revenues. As we have seen, with constant elasticity, the government does not choose such a distortion and has less incentive to do so when there are no revenues, as it is the case when agents only use electronic money

With full commitment, the "representative government" can credibly guarantee that $I_{t}^{e}=I_{t}^{b}-\theta \leq 1$ and, therefore, he always chooses to exercise this option. That is, with full commitment the analysis of the Ramsey problem reduces to the case, analyzed above, of $I_{t}^{e} \leq 1$.

\subsection{Optimal policy without commitment}

As we have seen, if $\sigma<1$, the Ramsey solution is time inconsistent, meaning that money is printed at a rate higher than the one consistent with Friedman rule. Nevertheless, if deviating from such path is costly enough for the "representative" government, then it may be a sequential equilibrium path; that is, it may be a credible policy. We now study under which conditions is the Friedman rule credible.

As it is well known, the Ramsey problem is not concave, so sufficient conditions for optimality cannot be obtained. However, if the maximum is interior and there is a unique solution to the necessary conditions (which is the case if the utility function exhibits CRRA), the Ramsey solution can be characterized as follows: Let $c(\tau)$ be the solution to

$$
u^{\prime}(c(\tau))=\alpha(1+\tau)
$$

$c(\tau)$ is the consumption of the credit and the cash goods, and let

$$
h(\tau)=1-(2 c(\tau)+g)
$$


and

$$
W(\tau)=[2 u(c(\tau))+\alpha h(\tau)] /(1-\beta)
$$

Similarly, let $c_{0}(\tau)$ be the solution to

$$
u^{\prime}\left(c_{0}(\tau)\right)=\frac{\alpha(1+\tau) \sigma}{1-(1-\sigma)(1+\tau)}
$$

and

$$
h_{0}(\tau)=1-\left(c_{0}(\tau)+c(\tau)+g\right)
$$

The solution for the cash good, (44) in period 0 is different from the solution for $t \geq 1$, (43) whenever $\sigma \neq 1$. Then, the consumption tax of the Ramsey solution is the value $\tau^{R}$ that satisfies

$g=\beta \tau^{R} 2 c\left(\tau^{R}\right)+(1-\beta) \tau^{R}\left(c_{0}\left(\tau^{R}\right)+c\left(\tau^{R}\right)\right)-(1-\beta)\left(\left(1+\tau^{R}\right) c_{0}\left(\tau^{R}\right)+d_{0} R_{0}^{b}\right)$

and the value of the Ramsey solution, $V_{0}^{R}$, is given by

$$
V_{0}^{R}=u\left(c_{0}\left(\tau^{R}\right)\right)+u\left(c\left(\tau^{R}\right)\right)+\alpha h_{0}\left(\tau^{R}\right)+\beta W\left(\tau^{R}\right)
$$

In order to compute the value, for the "representative" government of a deviation in period $t, t \geq 1$, let $c_{\theta}(\tau)$ be the solution to

$$
u^{\prime}\left(c_{\theta}(\tau)\right)=\alpha(1+\tau)(1+\theta)
$$

The demand for the cash good, from period $t+1$ on, is now affected by the cost of intermediation. Also let

$$
h_{\theta}(\tau)=1-\left(c(\tau)+(1+\theta) c_{\theta}(\tau)+g\right)
$$

where $\theta c_{\theta}(\tau)$ is the total intermediation cost. Let

$$
W^{D}(\tau)=\left[u(c(\tau))+u\left(c_{\theta}(\tau)\right)+\alpha h_{\theta}(\tau)\right] /(1-\beta) .
$$

In period $t$, when the deviation occurs, the private sector reacts immediately and currency is driven out of circulation. The way this happens is through an arbitrarily large price level. This also means that the real value of the outstanding electronic money is also made arbitrarily low. As a result the households are unable to consume the cash good, in that period. Therefore $h_{t}(\tau)=1-(c(\tau)+g)$ is the amount of leisure in period $t$. 
The deviation by the government causes a reversion to an equilibrium with electronic money only. This is an equilibrium where the real value of outstanding total money balances (including electronic money) is zero. Since the government must satisfy the budget constraint given the "strategy" of the households, that is taking into account how they react to the deviation, $\tau^{D}$ must be the solution to

$$
g=\beta \tau^{D} c_{\theta}\left(\tau^{D}\right)+\tau^{D} c\left(\tau^{D}\right)-(1-\beta) d_{t} \beta^{-1}
$$

Since the consumption of the cash good in period $t$ is zero, the government raises taxes from consumption of the credit good and from consumption of the cash good from period $t+1 \mathrm{on}$. The value of a deviation in period $t$, when the private agents react to the deviation by shifting to electronic money is given by

$$
V_{t}^{D}=u(0)+u\left(c\left(\tau^{D}\right)\right)+\alpha h_{t}\left(\tau^{D}\right)+\beta W^{D}\left(\tau^{D}\right)
$$

The budget constraint of the representative government in period $t \geq$ 1, (45), must be compared to the budget constraint corresponding to the Ramsey path for $t \geq 1$. This is

$$
g=2 \tau^{R} c\left(\tau^{R}\right)-(1-\beta)\left(1+\tau^{R}\right) c\left(\tau^{R}\right)-(1-\beta) d_{t} \beta^{-1}
$$

There are three differences between (45) and (46). The first is that $c_{\theta}\left(\tau^{D}\right)$ shows up instead of $c\left(\tau^{R}\right)$. This reflects the fact that after a deviation, consumers use electronic money to buy the cash good, which is dominated by currency at the Ramsey equilibrium. Therefore, consumption of the cash good following a deviation is lower than at the Ramsey solution. Note that this means that as the tax base will be lower, the tax rate must be higher, everything else constant. The second is that after a deviation, there is a liquidity crunch for one period, such that the government collects consumption taxes on the cash good only starting the next period. Thus, the value of the tax revenues is discounted by $\beta$. This also means that the tax base is lower, such that everything else constant,the tax must be higher. Finally, the third difference is that the second term in the right-hand-side of (46) is not present in (45). This is precisely the benefit of the deviation, the destruction of the real value of outstanding currency. In this case, everything else constant, the after deviation tax must be lower. Note that if the two first effects dominate, 
the tax after a deviation is higher than the Ramsey tax, so a deviation lowers the utility of the government, which means that the Ramsey allocation is sustainable. An example is when $\beta$ is made arbitrarily close to one. Then, it must be that $\tau^{R} \leq \tau^{D}$, with equality when $\theta$ is made arbitrarilly close to zero. In the case of equality, the value of the deviation is lower than the value of the Ramsey solution because of the liquidity crunch.

When the gains from the initial destruction of real liabilities are enough to induce $\tau^{R}>\tau^{D}$, then this effect must be compared with the costs of making the consumption of the cash good too low - the liquidity crunch-, as well as the waste in resources from using electronic money in transactions rather than using the more efficient currency. If the costs outweight the benefits, $V_{t}^{R} \geq V_{t}^{D}$, where $V_{t}^{R}=W\left(\tau^{R}\right), t \geq 1$, and the Ramsey solution is a sequential equilibrium path. In particular, the Friedman rule is sustainable if the discount factor and the intermediation costs are not too low and the liquidity crunch factor, of having $u(0)$ instead of $u\left(c\left(\tau^{R}\right)\right.$, results in a severe loss of utility. For example, this is the case when utility takes the CRRA form and $\sigma>1$, so $u(0)=-\infty$.

Reserve requirements have no effect on the Ramsey solution. This solution is the Friedman rule and electronic money does not circulate. However, as we saw in section 4.2., the presence of the reserve requirements can increase the punishment, to the disutility of autarchy, since this would be an equilibrium with an arbitrarily large nominal interest rate. This would help sustain the commitment solution.

In summary, when governments are benevolent, electronic money reduces the punishment of a deviation and therefore makes it harder to sustain the optimal solution. However the punishment might still be big enough, so that the Friedman rule can still be the outcome of a sequential equilibrium. The punishments can be made substantially more severe with reserve requirements. 


\section{Conclusions}

\subsection{Electronic money: "Representative" governments vs rent-seeking governments}

In this paper we have seen how the role of electronic money competition as a disciplinary mechanism is fairly different depending on the preferences of the government, the commitment technology, etc. In particular, the introduction of electronic money affects the returns of the profit maximizing government by competing away some of the monopolistic rents and, as a result, lowering the equilibrium inflation rates in the full commitment equilibrium. When there is not full commitment, the cost from deviating for a profit maximizing government is simply the loss of future seignorage rents. The presence of electronic money does not affect the revenues of the government after a deviation, since the seignorage revenues are zero independently of whether households can or can not substitute currency for other liquid assets. Nevertheless, with lower gains - due to the presence of electronic money - the relative cost is also lower and, hence, higher the incentive to deviate. However, if financial intermediation is costly enough, a profit maximizer government will not deviate from the full commitment path.

In contrast, with a "representative" government, the introduction of electronic money does not affect the returns of the government since, under full commitment, the Ramsey policy prescription is the Friedman rule and electronic money is -asset return- dominated by the government currency. However, the presence of electronic money affects the value -to the governmentof the equilibrium path after a deviation. Since the government shares the preferences of the household, and the household is better off when is able to consume cash goods with electronic money (and, therefore, the tax base is wider), the "punishment" after a deviation is not so severe, and the incentive to deviate higher, when there is electronic money. But, as we have seen, the liquidity crunch effect may be enough of a deterrence to prevent the "repre-

sentative" government to deviate from the Ramsey policy even when there is electronic money.

In both cases, whether the government is "representative" or profit maximizer, if a deviation from the full commitment solution takes place (because the deterrence effects are not strong enough) households are better off if electronic money is in existence (e.g., the relation between cash and credit goods 
is less distorted). There is, however, a region of parameters where deviations will take place with electronic money and will not take place without its presence, only in this region may a world without electronic money be preferred by households.

Reserve requirements affect the competition between currency and electronic money. With reserve requirements the rents in the full commitment solution with a revenue maximizing government are higher, and the costs of a deviation from the Friedman rule path with a welfare maximizing government are also higher. So reserve requirements make it easier to sustain the commitment solutions, which may result in a welfare improvement, when the government is revenue maximizer. Similarly, reserve requirements can make the deviation paths more harmful to a "representative" government, in the presence of electronic money. That is, our analysis also provides prescriptions for the use of reserve requirements as policy instruments, even if our deterministic, perfect information, economies are absent of the problems that usually justify their existence.

In summary, our analysis shows how, in general, electronic money competition may enhance efficiency. That is, our results further question the "natural monopoly" view in monetary theory, even though they can not be seen either as a blank endorsement of the "currency competition" view. Not only we have shown that there are cases in which competition may not be desirable, but also that when electronic money competition enhances efficiency the resulting outcome is not, in general, the Friedman rule of zero nominal interest rates, as many proposers - notably, Hayek $(1974,78)$ - have postulated.

\subsection{Reputation, competition and "the end of inflation"}

Our analysis shows how two disciplinary mechanisms: "competition" and "reputation" can interact in fairly complex ways and, in some cases, undermine each other. This, we believe, is a general feature of the interplay between competition and reputation and electronic money competition is a particular reflection of it.

While this paper suggests many new inquires, there are two, in particular, that we want to pursue. First, the analysis of "currency competition" in its strict sense. With this our analysis will be in closer line with the historical debate on currency competition (see White, 1993), but it can also give some 
light on policy issues in a world in which, due to the globalization of financial markets, different government currencies become close substitutes. For example, with the constitution of the EMU, countries that, for some reason, do not form part of the monetary union, but have close links with it may, in practice, be in a situation of close substitutability of the national currency with the euro.

Second, as we have pointed out at the beginning, our analysis also suggests that electronic money competition may have had (or have, in the future) an important role in bringing down inflation, a role that may have been undervalued. Such a quantitative assessment can have interesting policy implications. Current thinking about policy design aimed at sustaining price stability -for example, implicit in the Maastricht Treaty- assigns a major role to the proper separation of monetary decisions from fiscal pressures, to implementing constraints on fiscal policies, etc. Little attention is paid to the evolution (and design) of payments systems, our analysis suggests that attention should be paid, a quantitative analysis may give a measure of its importance. 


\section{References}

[1] Abreu, Dilip, 1988, "On the Theory of Infinitely Repeated Games With Discounting", Econometrica, 56, 383-396.

[2] Atkinson, A. B. and J. E. Stiglitz, 1972, "The Structure of Indirect Taxation and Economic Efficiency", Journal of Public Economics, 1, $97-11$.

[3] Black, Fisher, 1970, "Banking and Interest Rates in a World Without Money", Journal of Bank Research, 1, 9-20 (also in White (1993) v. III, 168-179)

[4] Barro, Robert J. and Gordon, D.B., 1983, "Rules, Discretion and Reputation in a Model of Monetary Policy", Journal of Monetary Economics, $12,101-121$.

[5] Becker, Gary S. 1956, "A Proposal for Free Banking", unpublished manuscript, University of Chicago, in White (1993) v. III, 20-25.

[6] Calvo, Guillermo, 1978, "On the Time Consistency of Optimal Policy in a Monetary Economy", Econometrica, 46, 1411-1428.

[7] Calomiris, Charles W. and Charles M. Kahn, 1996, "The Efficiency of Self-Regulated Payments Systems: Learning from the Suffolk System," Journal of Money, Credit and Banking, 28 (4), 766-797.

[8] Chari, V.V. and Patrick Kehoe, P. (1990), "Sustainable Plans", Journal of Political Economy, 98, 783-802.

[9] Chari, V. V., Lawrence J. Christiano and Patrick J. Kehoe, 1993, "Optimality of the Friedman Rule in Economies with Distorting Taxes", Federal Reserve Bank of Minneapolis Staff Report 158.

[10] Chang, Roberto, 1996, "Credible Monetary Policy with Long-Lived Agents: Recursive Approaches", Federal Reserve Bank of Atlanta, wp. 96-20.

[11] Checkland, S.G., 1975, "Adam Smith and the Bankers", in A. S. Skinner ad T. Wilson (eds.), Essays on Adam Smith, Clarendon Press, London, 504-523 (also in White (1993) v. II, 3-22). 
[12] Dowd, Kevin (ed.), 1992, The Experience of Free Banking, Routledge, London.

[13] Friedman, Milton, 1960, A Program for Monetary Stability, Fordham Univ. Press., New York.

[14] Friedman, Milton, 1969, "The Optimum Quantity of Money", in M. Friedman, ed., The Optimum Quantity of Money and other Essays, Aldine, Chicago, Il..

[15] Friedman, Milton and Anne J. Schwartz, 1986, "Has Government any Role in Money?" Journal of Monetary Economics, 17 (1), 37-62 (also in White (1993) v. III, 348-373).

[16] Hayek, F.A., 1974, Choice in Currency: A Way to Stop Inflation. The Institute of Economic Affairs, London.

[17] Hayek, F.A., 1978, Desnationalisation of Money: The Argument Refined. The Institute of Economic Affairs, London.

[18] Hellwig, Martin F., 1985, "What Do We Know About Currency Competition?", Zeitschrift fur Wirtschafts- und Sozialwissenschaften, 5, 565-88 (also in White (1993) v. III, 324-347).

[19] Humphrey, David B, Lawrence B. Pulley and Jukka M. Vesala, 1996, "Cash, Paper, and Electronic Payments: A Cross-Country Analysis", Journal of Money, Credit and Banking, 28, 914-939.

[20] Ireland, Peter N., 1994, "Sustainable Monetary Policies", mimeo, Research Department, Federal Reserve Bank of Richmond.

[21] Kehoe, Patrick J., 1989, Policy Cooperation Among Benevolent Governments may be Undesirable, Review of Economic Studies 56, 289-296.

[22] King, Robert G., 1983, "On the Economics of Private Money", Journal of Monetary Economics, 12 (1), 127-58 (also in White (1993) v. II, 146-177). .

[23] Lucas, Robert E., Jr., 1993, "The Welfare Cost of Inflation", mimeo, The University of Chicago. 
[24] Lucas, Robert E., Jr. and Nancy L. Stokey, 1983, "Optimal Fiscal and Monetary Theory in an Economy without Capital", Journal of Monetary Economics, 12, 55-93.

[25] Nicolini, Juan Pablo, 1997, "More on the Time Inconsistency of Optimal Monetary Policy", Journal of Monetary Economics, forthcoming.

[26] Ramsey, Frank P., 1927, "A Contribution to the Theory of Taxation", Economic Journal 37, 47-61.

[27] Rockoff, H.,1975, The Free Banking Era: A Reconsideration (New York: Arno Press).

[28] Rolnick, Arthur J. and Warren E. Weber (1983), "New Evidence on the Free Banking Era", American Economic Review, 73 (5), 1080-91 (also in White (1993) v. II, 178-189).

[29] Schuler, K., 1992, "The World of Free Banking", in Dowd (1992).

[30] Selgin, George A. 1987, "The Stability and Efficiency of Money Supply Under Free Banking Systems", Journal of Institutional and Theoretical Economics, 143 (3), 435-456 (also in White (1993) v. III, 45-66).

[31] Selgin, George A. and Lawrence H. White, 1987, "The Evolution of a Free banking System", Economic Inquiry, XXV (3), 439-57 (also in White (1993) v. III, 26-44).

[32] Stokey, Nancy, 1991, "Credible Public Policy", Journal of Economic Dynamics and Control, 15, 627-656.

[33] Svensson, L.E.O., 1985, "Money and Asset Prices in a Cash-in-Advance Economy", Journal of Political Economy, 93, 919-944.

[34] Taub, B. (1985), "Private Fiat Money with Many Suppliers", Journal of Monetary Economics, 16, 195-208 (also in White (1993) v. III, 135-148).

[35] Tobin, James, 1963, "Comercial banks as Creators of Money", in d. Carson (ed.) Banking and Monetary Studies, Homewood, Il: Irwin, 408419 . 
[36] Vaubel, 1985, "Competing Currencies: The Case for Free Entry", Zeitschrift fur Wirtschafts- und Sozialwissenschaften, 5, 565-88 (also in White (1993) v. III, 306-323).

[37] Wallace, Neil, 1983, "A Legal Restrictions Theory of the Demand for "Money" and the Role of Monetary Policy", Federal Reserve Bank of Minneapolis Quarterly Review, Winter, 1-7 (also in White (1993) v. III, 217-223).

[38] Wallace, Neil, 1988, "A Suggestion for Oversimplifying the Theory of Money", Economic Journal, 98 (390), 25-36 (also in White (1993) v. III, 246-257).

[39] White, Lawrence H., 1989, Competition and Currencies, New York University Press, New York.

[40] White, Lawrence H. (ed.), 1993, Free Banking, vols. I, II \& III, E. Elgar Publ. Aldershot Hants, UK.

[41] Woodford, Michael, 1995, "Price-Level Determinacy Without Control of a Monetary Aggregate", Carnegie-Rochester Conference Series on Public Policy, 1-46. 